Provided for non-commercial research and education use. Not for reproduction, distribution or commercial use.



This article appeared in a journal published by Elsevier. The attached copy is furnished to the author for internal non-commercial research and education use, including for instruction at the authors institution and sharing with colleagues.

Other uses, including reproduction and distribution, or selling or licensing copies, or posting to personal, institutional or third party websites are prohibited.

In most cases authors are permitted to post their version of the article (e.g. in Word or Tex form) to their personal website or institutional repository. Authors requiring further information regarding Elsevier's archiving and manuscript policies are encouraged to visit:

http://www.elsevier.com/copyright 
Phase III randomised trial

\title{
First results of the randomised UK FAST Trial of radiotherapy hypofractionation for treatment of early breast cancer (CRUKE/04/015)
}

\author{
The FAST Trialists group ${ }^{1}$
}

\section{A R T I C L E I N F O}

\section{Article history:}

Received 6 May 2011

Received in revised form 10 June 2011

Accepted 11 June 2011

Available online 11 July 2011

\section{Keywords:}

Breast cancer

Radiotherapy

Hypofractionation

\begin{abstract}
A B S T R A C T
Background and purpose: Randomised trials testing 15- or 16-fraction regimens of adjuvant radiotherapy in women with early breast cancer have reported favourable outcomes compared with standard fractionation. To evaluate hypofractionation further, two 5 -fraction schedules delivering 1 fraction per week have been tested against a 25 -fraction regimen.

Materials and methods: Women aged $\geqslant 50$ years with node negative early breast cancer were randomly assigned after microscopic complete tumour resection to $50 \mathrm{~Gy}$ in 25 fractions versus 28.5 or $30 \mathrm{~Gy}$ in 5 once-weekly fractions of 5.7 or $6.0 \mathrm{~Gy}$, respectively, to the whole breast. The primary endpoint was 2-year change in photographic breast appearance.

Results: Nine hundred and fifteen women were recruited from 2004 to 2007. Seven hundred and twentynine patients had 2-year photographic assessments. Risk ratios for mild/marked change were 1.70 ( $95 \% \mathrm{CI}$ $1.26-2.29, p<0.001)$ for $30 \mathrm{~Gy}$ and $1.15(0.82-1.60, p=0.489)$ for $28.5 \mathrm{~Gy}$ versus $50 \mathrm{~Gy}$. Three-year rates of physician-assessed moderate/marked adverse effects in the breast were $17.3 \%(13.3-22.3 \%, p<0.001)$ for $30 \mathrm{~Gy}$ and $11.1 \%(7.9-15.6 \%, p=0.18)$ for $28.5 \mathrm{~Gy}$ compared with $9.5 \%(6.5-13.7 \%)$ after $50 \mathrm{~Gy}$. With a median follow-up in survivors of 37.3 months, 2 local tumour relapses and 23 deaths have occurred. Conclusion: At 3 years median follow-up, $28.5 \mathrm{~Gy}$ in 5 fractions is comparable to 50 Gy in 25 fractions, and significantly milder than $30 \mathrm{~Gy}$ in 5 fractions, in terms of adverse effects in the breast.
\end{abstract}

(c) 2011 Elsevier Ireland Ltd. All rights reserved. Radiotherapy and Oncology 100 (2011) 93-100
The traditional model of fractionation sensitivity assumes tumours to be relatively unresponsive to fraction size compared with late reacting normal tissues [1]. Sensitivity to fraction size is conveniently described by the $\alpha / \beta$ value, which is relatively high ( $\geqslant 6 \mathrm{~Gy}$ ) for many squamous carcinomas and early responding normal tissues compared to late responding normal tissues $(\alpha / \beta$ values $<6 \mathrm{~Gy}$ ). This relationship does not apply to all tumour types, with evidence that adenocarcinomas of the breast and prostate are more sensitive to fraction size than previously thought [2]. An $\alpha / \beta$ value of 4-5 Gy was first estimated for locally advanced and recurrent breast cancer by Douglas in the mid-1980s based on clinical data published by Cohen in early 1950s [3,4]. A recent estimate of 4.6 Gy (95\% CI 1.1-8.1) was reported for the fractionation sensitivity of breast cancer in the adjuvant setting, based on combined results of the START pilot and START A randomised trials $[5,6]$. The results of the Ontario and START B trials evaluating fractions of $2.67 \mathrm{~Gy}$ are consistent with this estimate $[7,8]$. If true, there is no advantage in using $\leqslant 2.0 \mathrm{~Gy}$ fractions, which are as gentle on the cancer as on the dose-limiting normal tissues. There are obvious advantages in terms of convenience and cost to patients prescribed

\footnotetext{
${ }^{1}$ Corresponding author. John R. Yarnold, Academic Radiotherapy, The Institute of Cancer Research, 15 Cotswold Road, Sutton SM2 5PT, UK. E-mail address: john.yarnold@icr.ac.uk (J.R. Yarnold).
}

fewer fractions of radiotherapy. If treatment time is shortened, there may also be benefits in terms of tumour control.

Five fractions of 5.7 or $6.0 \mathrm{~Gy}$ are predicted by the linear quadratic model to be equivalent to 25 fractions of $2.0 \mathrm{~Gy}$, assuming values for $\alpha / \beta$ of 3.0 and $4.0 \mathrm{~Gy}$, respectively [9]. Based on early and late human skin responses, the linear-quadratic model appears to perform reliably over this range of radiation fraction sizes [10]. There is limited human experience of once-weekly fractionation in breast cancer radiotherapy based on $6.5 \mathrm{~Gy}$ fractions to the breast reported by French colleagues. In 115 patients undergoing primary radiotherapy for non-metastatic breast cancer, five once-weekly doses of $6.5 \mathrm{~Gy}$ to the whole breast (reference point unspecified) were followed in 101 women by 1-3 tumour bed boost doses of 6.5 Gy [11]. Late effects, most commonly induration, were classified as grade 1 in 19 cases, grade 2 in 21 cases and grade 3 in 6 patients at a median of 41 months. In another French series, 50 patients were given 5 once-weekly fractions of $6.5 \mathrm{~Gy}$ to the whole breast as adjuvant therapy after breast conservation surgery, without a tumour bed boost dose [12]. Grade 1 or 2 induration was reported in $33 \%$ of the patients at a median follow up of 93 months (range 9-140), and no grade 3 or 4 effects were reported. Assuming an $\alpha / \beta$ value of $3 \mathrm{~Gy}$ for late adverse effects, 5 fractions of $6.5 \mathrm{~Gy}$ are equivalent to $62 \mathrm{~Gy}$ in $2.0 \mathrm{~Gy}$ fractions, a high dose intensity in the adjuvant setting. These data are encouraging, in terms of 
safety, but randomised trials are needed to formally test fraction sizes in the range of 5.0-6.0 Gy. Against this background, the randomised FAST Trial was conducted, comparing 5 once-weekly fractions of $5.7 \mathrm{~Gy}$ and $6.0 \mathrm{~Gy}$ against 25 daily fractions of $2.0 \mathrm{~Gy}$ in terms of late normal tissue effects and tumour control, in women prescribed whole breast radiotherapy (no boost) after local excision of early breast cancer. Once-weekly fractions were chosen to minimise confounding by differences in treatment time. Two test dose levels were chosen to allow interpolation, if necessary, in order to identify a 5-fraction regimen iso-effective with the control schedule.

\section{Materials and methods}

\section{Patients}

The trial was open to women with early stage breast cancer and favourable prognostic features including age $\geqslant 50$ years, invasive carcinoma, breast conserving surgery, pathological tumour size $<3.0 \mathrm{~cm}$, complete microscopic resection of tumour and negative axillary node status established by appropriate surgical staging. Patients with oestrogen positive tumours were eligible for adjuvant endocrine therapy. Exclusion criteria included mastectomy, lymphatic radiotherapy, tumour bed boost dose and neoadjuvant or adjuvant cytotoxic therapy. Patients were recruited from 18 UK radiotherapy centres.

Eligible patients were randomised after written informed consent in a $1: 1: 1$ ratio to $50 \mathrm{~Gy}$ in 25 fractions of $2.0 \mathrm{~Gy}$ (Control group) versus $30 \mathrm{~Gy}$ in 5 fractions of $6.0 \mathrm{~Gy}$ (Test group 1 ) versus $28.5 \mathrm{~Gy}$ in 5 fractions of $5.7 \mathrm{~Gy}$ (Test group 2), all over 5 weeks. Randomisation was performed by telephone or facsimile from the recruiting centre to the Clinical Trials and Statistics Unit, Institute of Cancer Research (ICR-CTSU), Sutton. Treatment allocation used computer-generated random permuted blocks stratified by participating centre. Treatment allocation could not be blinded due to the nature of the intervention (i.e. different radiotherapy schedules).

All patients provided written informed consent. FAST (CRUKE) 04/015) was approved by the national South-West Multicentre Research Ethics Committee (04/MRE06/17) and the local ethics committees of all participating centres. Our trial was sponsored by The Institute of Cancer Research and undertaken in accordance with the principles of Good Clinical Practice. This study is registered as an International Standard Randomised Controlled Trial, number ISRCTN62488883.

\section{Radiotherapy}

There were no constraints on breast size written in the protocol. Patients lay in the same supine position, typically on an inclined plane, for treatment planning, simulation and treatment. Some form of immobilisation device, such as a breast board, was highly recommended, and reproducibility of the position was verified by orthogonal laser beams. The clinical target volume included the soft tissues of the whole breast down to the deep fascia, but did not include underlying muscle and ribcage, nor overlying skin and excision scar. The planning target volume (PTV) included the entire breast with $1 \mathrm{~cm}$ margin to visible and palpable breast tissue. Medial and lateral borders did not normally extend beyond the anterior midline or the mid-axilla. These margins were reduced in selected patients to minimise the volume of heart and/or lung in the high dose zone, provided the tumour bed was not excluded. The deep margin extended down to the deep fascia, but the treatment volume inevitably included the underlying pectoralis major muscle and ribcage.

Transverse cross-sections of the patient were taken through the centre of the PTV, using computerised tomography where avail- able; otherwise, accurate external contours were acceptable. The maximum thickness of lung included in the tangential field was $2.0 \mathrm{~cm}$, defined by computerised tomography or simulator. Cardiac shielding was introduced using a multileaf collimator, or other shielding technique, whenever appropriate. The dose distribution across the PTV was modified in accordance with ICRU guidelines $[13,14]$. If the maximum dose was $>107 \%$, full dose compensation was introduced. Doses were prescribed to the reference point at or near the centre of the target volume. This point was half-way between the lung surface and the skin surface on the perpendicular bisector of the posterior beam edge. Maximum and minimum doses were also recorded, and the difference between these could be no more than $10 \%$ on the central plane. Megavoltage photons were required in all patients, most commonly $6 \mathrm{MV}$, recognising that tangential fields with large baseline separations might be best encompassed with 8-10 MV energies.

\section{Outcome assessment}

The primary endpoint was change in photographic breast appearance, and secondary endpoints included clinical assessments of radiation-induced changes in the breast, and local tumour control, the latter endpoints recorded via a case report form completed annually for each patient.

Photographic assessments were planned at baseline and at years 2 and 5 . Two frontal views of the chest were taken, one with hands on the hips and the other with hands raised as far as possible above the head. Change in breast appearance compared with the post-surgical (pre-radiotherapy) baseline was scored on a threepoint graded scale (corresponding to none, mild and marked change), based on changes in size, shrinkage and shape. No further photographs were taken in patients who had relapsed, as change in photographic breast appearance from the pre-radiotherapy baseline would be unevaluable following further treatment. Breast size and surgical deficit were scored from the baseline photographs on arbitrary three-point graded scales (small, medium and large). As a rough guide, the 3 grades of breast size correspond to breast volumes in the range $<500,500-1000$ and $>1000$ cubic centimetres, respectively. Surgical deficit represents the reduction in breast size as a result of the primary surgery; the 3 grades of surgical deficit correspond to subtle or no visible difference in the size of each breast, a difference that would not be obvious when wearing tight clothing and a difference that would be obvious in tight clothing, respectively. All photographs were scored by three observers blind to patient identity and treatment allocation; the procedures for this scoring mechanism were established in the START Trials [15]. Late-occurring adverse tissue effects (including breast shrinkage, induration, telangiectasia, breast oedema, symptomatic rib fracture, symptomatic lung fibrosis and ischaemic heart disease) were assessed by physicians at the annual follow-up visits, and graded on a 4-point scale (none, a little, quite a bit and very much), as in the START Trials. There was no blinding to randomised treatment allocation in the physician assessments. No patient selfassessments were included in the trial protocol, partly for resource reasons, but also because the study was designed as a dose-finding study for a future phase 3 trial.

Clinical assessments of acute skin toxicity were added to the trial data collection part-way through accrual, hence are not available for all trial patients. Data on early skin reactions were collected over the treatment period and the maximum score recorded using the RTOG graded scale $(0=$ no visible change; $1=$ faint/dull erythema; $2=$ tender/bright erythema \pm dry desquamation; 3 = patchy moist desquamation; $4=$ confluent moist desquamation, pitting oedema) [16].

Tumour relapse and new ipsilateral primary tumour required confirmation by pathological assessment. Ipsilateral local tumour 
relapse was defined as a cancer originating in the ipsilateral breast parenchyma and/or overlying skin. The following events were also recorded: regional metastases (axilla, supraclavicular fossa and internal mammary chain), haematogenous metastases (only details of the first relapse recorded) and death.

\section{Sample size}

Using results from the START pilot trial [5], an average 2-year rate of mild or marked change in photographic breast appearance for the test groups of $20 \%$ was assumed. Randomisation of 900 patients (300 per treatment group) would allow an absolute $10 \%$ difference in the probability of a change in photographic breast appearance between test dose levels to be detected with $90 \%$ power at the $5 \%$ significance level (2-sided test). Assuming linearity between the two dose levels of the test groups, the analysis would also allow interpolation (and limited degrees of extrapolation if necessary) to determine the experimental schedule equivalent to daily fractions of $2.0 \mathrm{~Gy}$. The estimate of sample size allowed for $10 \%$ loss to follow-up/unevaluable.

\section{Statistical methods}

Scores from the 2-year photographic assessments of change in breast appearance and the assessments of acute skin toxicity were compared between pairs of trial treatment groups using the $\chi^{2}$ test and $\chi^{2}$ test for trend. The endpoint of any change in photographic breast appearance was defined as mild or marked change versus none. In the START pilot trial and START trials, the 2-year outcome data proved to be a reliable predictor of relative effect at time-points up to at least 5 years $[6,7,17]$. For the physician assessments of late adverse effects, an event was defined as the first occurrence of a moderate or marked symptom (graded "quite a bit" or "very much"). Adverse events reported at the year 1 annual physician assessment were not included in the analysis as these are more likely to reflect transient surgical and/or radiotherapy effects rather than permanent change. Survival analysis methods were used to compare rates of physician assessments of moderate or marked adverse effects between the schedules, with length of follow-up calculated from randomisation to time of first event or last follow-up assessment, whichever was sooner. Kaplan-Meier survival plots and estimates of annual rates of moderate or marked adverse effects according to trial treatment group were constructed for each type of effect and treatment schedules compared using the pairwise logrank test.

Direct estimates of the $\alpha / \beta$ value for the different endpoints of late adverse effects were obtained in each case by fitting a Cox proportional hazards regression model containing terms for total dose, and total dose multiplied by fraction size. The $\alpha / \beta$ ratio was calculated by dividing the two parameter estimates (estimate for total dose/estimate for total dose $\times$ fraction size), and approximate $95 \%$ CI for the $\alpha / \beta$ estimates were calculated using Taylor series expansion for the covariance of a ratio of two random variables. Lower limits of CIs for the $\alpha / \beta$ estimates were truncated at zero when the calculated limit was negative. Since the number of relapses and deaths were small at this stage of the trial the analysis was purely descriptive.

All analyses were done on an intention-to-treat basis.

\section{Role of the funding source}

The funding source provided peer-reviewed approval for the trial but had no other role in study design, collection, analysis, interpretation of data, or writing of the report. JRY, JSH, JPM and
JMB had full access to all of the data. JRY had final responsibility for the decision to submit for publication.

\section{Results}

Between October 2004 and March 2007, 915 women were recruited from 18 radiotherapy centres in the UK. Clinical and demographic details of the patients at randomisation appeared similar between groups (Table 1). Compliance of annual follow-up forms for years $1-3$ was $99.0 \%, 97.4 \%$ and $85.4 \%$, respectively, with no difference in compliance between treatment groups. At the time of the analysis, median follow-up in surviving patients was

Table 1

Baseline characteristics by randomised fractionation schedule.

\begin{tabular}{|c|c|c|c|}
\hline & $\begin{array}{l}50 \text { Gy } \\
N=302(\%)\end{array}$ & $\begin{array}{l}30 \mathrm{~Gy} \\
N=308(\%)\end{array}$ & $\begin{array}{l}28.5 \mathrm{~Gy} \\
N=305(\%)\end{array}$ \\
\hline $\begin{array}{l}\text { Age (years) } \\
50-59 \\
60-69 \\
70-79 \\
80- \\
\text { Mean (SD) } \\
\text { [Range] }\end{array}$ & $\begin{array}{l}112(37.1) \\
143(47.4) \\
44(14.6) \\
3(1.0) \\
63.1(7.2) \\
{[50.0-88.4]}\end{array}$ & $\begin{array}{l}112(36.4) \\
145(47.1) \\
42(13.6) \\
9(2.9) \\
62.9(7.5) \\
{[50.1-84.9]}\end{array}$ & $\begin{array}{l}110(36.1) \\
153(50.2) \\
39(12.8) \\
3(1.0) \\
62.7(6.8) \\
{[50.0-82.3]}\end{array}$ \\
\hline $\begin{array}{l}\text { Time from surgery to randomis } \\
\text { Median (interquartile range) } \\
\text { [Range] }\end{array}$ & $\begin{array}{l}\text { tion (weeks) } \\
6.0(4.4-7.6) \\
{[1.3-22.1]}\end{array}$ & $\begin{array}{l}5.7(4.1-7.2) \\
{[0.4-21.1]}\end{array}$ & $\begin{array}{l}6.0(4.1-7.6) \\
{[0.7-19.0]}\end{array}$ \\
\hline $\begin{array}{l}\text { Histological type } \\
\text { Ductal } \\
\text { Lobular } \\
\text { Special type } \\
\text { Mixed } \\
\text { DCIS } \\
\text { Other }\end{array}$ & $\begin{array}{l}230(76.2) \\
36(11.9) \\
22(7.3) \\
10(3.3) \\
3(1.0) \\
1(0.3)\end{array}$ & $\begin{array}{l}241(78.2) \\
29(9.4) \\
31(10.1) \\
7(2.3) \\
0(0.0) \\
0(0.0)\end{array}$ & $\begin{array}{l}229(75.1) \\
30(9.8) \\
29(9.5) \\
15(4.9) \\
1(0.3) \\
1(0.3)\end{array}$ \\
\hline $\begin{array}{l}\text { Axillary surgery } \\
\text { None } \\
\text { SNB } \\
\text { Sampling } \\
\text { Clearance } \\
\text { SNB and sampling } \\
\text { SNB and clearance } \\
\text { Other }\end{array}$ & $\begin{array}{l}1(0.3) \\
49(16.2) \\
140(46.0) \\
85(28.1) \\
24(7.9) \\
1(0.3) \\
2(0.7)\end{array}$ & $\begin{array}{l}0 \\
52(16.9) \\
133(43.2) \\
85(27.6) \\
35(11.4) \\
2(0.6) \\
1(0.3)\end{array}$ & $\begin{array}{l}3(1.0) \\
57(18.7) \\
134(43.9) \\
80(26.2) \\
28(9.2) \\
2(0.6) \\
1(0.3)\end{array}$ \\
\hline $\begin{array}{l}\text { Pathological tumour size }(\mathrm{cm}) \\
\quad<1 \\
1-2 \\
\geqslant 2 \\
\text { Mean (SD) } \\
\text { [Range] }\end{array}$ & $\begin{array}{l}90(29.8) \\
166(55.0) \\
46(15.2) \\
1.3(0.6) \\
{[0.05-3.0]}\end{array}$ & $\begin{array}{l}84(27.3) \\
165(53.6) \\
59(19.2) \\
1.3(0.6) \\
{[0.13-3.0]}\end{array}$ & $\begin{array}{l}87(28.5) \\
160(52.5) \\
58(19.0) \\
1.3(0.7) \\
{[0.1-3.0]}\end{array}$ \\
\hline $\begin{array}{l}\text { Tumour grade } \\
1 \\
2 \\
3 \\
\text { Not known }\end{array}$ & $\begin{array}{l}94(31.1) \\
176(58.3) \\
29(12.9) \\
3(1.0)\end{array}$ & $\begin{array}{l}113(36.7) \\
159(51.6) \\
35(11.4) \\
1(0.3)\end{array}$ & $\begin{array}{l}102(33.4) \\
168(55.1) \\
34(11.1) \\
1(0.3)\end{array}$ \\
\hline $\begin{array}{l}\text { Adjuvant therapy } \\
\text { None } \\
\text { Tamoxifen } \\
\text { AI } \\
\text { Tamoxifen } \rightarrow \text { AI } \\
\text { Unknown type }\end{array}$ & $\begin{array}{l}39(12.9) \\
227(75.2) \\
31(10.3) \\
4(1.3) \\
1(0.3)\end{array}$ & $\begin{array}{l}37(12.0) \\
243(78.9) \\
26(8.4) \\
2(0.6) \\
0(0.0)\end{array}$ & $\begin{array}{l}30(9.8) \\
224(73.4) \\
45(14.8) \\
4(1.3) \\
2(0.7)\end{array}$ \\
\hline $\begin{array}{l}\text { Breast size } \\
\text { Small } \\
\text { Medium } \\
\text { Large } \\
\text { Unknown }\end{array}$ & $\begin{array}{l}154(51.0) \\
89(29.5) \\
38(12.6) \\
21(7.0)\end{array}$ & $\begin{array}{l}172(55.8) \\
87(28.2) \\
31(10.1) \\
18(5.8)\end{array}$ & $\begin{array}{l}163(53.4) \\
93(30.5) \\
24(7.9) \\
23(7.5)\end{array}$ \\
\hline $\begin{array}{l}\text { Surgical deficit } \\
\text { Small } \\
\text { Medium } \\
\text { Large } \\
\text { Unknown } \\
\text { a }\end{array}$ & $\begin{array}{l}156(51.7) \\
68(22.5) \\
57(18.9) \\
21(7.0)\end{array}$ & $\begin{array}{l}148(48.1) \\
83(26.9) \\
59(19.2) \\
18(5.8)\end{array}$ & $\begin{array}{l}154(50.5) \\
77(25.2) \\
51(16.7) \\
23(7.5)\end{array}$ \\
\hline
\end{tabular}

a Breast size and surgical deficit scored from baseline photographs. Unknown indicates no baseline photograph available. 
37.3 months; follow-up is ongoing. Twelve patients did not receive their allocated treatment, 3 withdrew following randomisation and 4 moved before follow-up data were obtained (Fig. 1). There were 3 reports of unusual severe acute radiotherapy reactions, all in the $28.5 \mathrm{~Gy}$ group, 2 of which have resolved over time. All involved changes in the skin appearing at the end of week $5(n=1)$ or 6 $(n=2)$, including patchy desquamation $(n=1)$, possible cellulitis $(n=1)$ and breast oedema $(n=1)$. On review, these were not considered unusual or severe. Data on acute skin reactions collected on 327 consecutive patients demonstrate milder acute reactions in both 5 -fraction test groups (Table 2).
Assessments of 2-year change in photographic breast appearance were available for 729 (81\%) patients out of the 901 still alive and disease-free, see Fig. 1. Change in photographic breast appearance at 2 years according to fractionation regimen indicated a clear and statistically significant dose response between 28.5 and $30 \mathrm{~Gy}$ (Table 3 ) and the apparent comparability of the $28.5 \mathrm{~Gy}$ test dose level with $50 \mathrm{~Gy}$ in 25 fractions. The risk ratio for mild or marked change in 2-year photographic breast appearance for $30 \mathrm{~Gy}$ versus $50 \mathrm{~Gy}$ was 1.70 (95\% CI 1.26-2.29, $p<0.001)$ and for $28.5 \mathrm{~Gy}$ versus $50 \mathrm{~Gy}$ was 1.15 (95\% CI $0.82-1.60, p=0.489)$. Similar relationships between schedules were confirmed by the analysis
Number randomised

\section{Allocated fractionation schedule}

Received allocated treatment as per protocol

(Only major treatment deviations listed. Minor deviations due to public holidays, machine service days and machine breakdowns not included).

\section{Baseline photographic assessment available}

Year 2 photographic assessment available

Follow-up data available

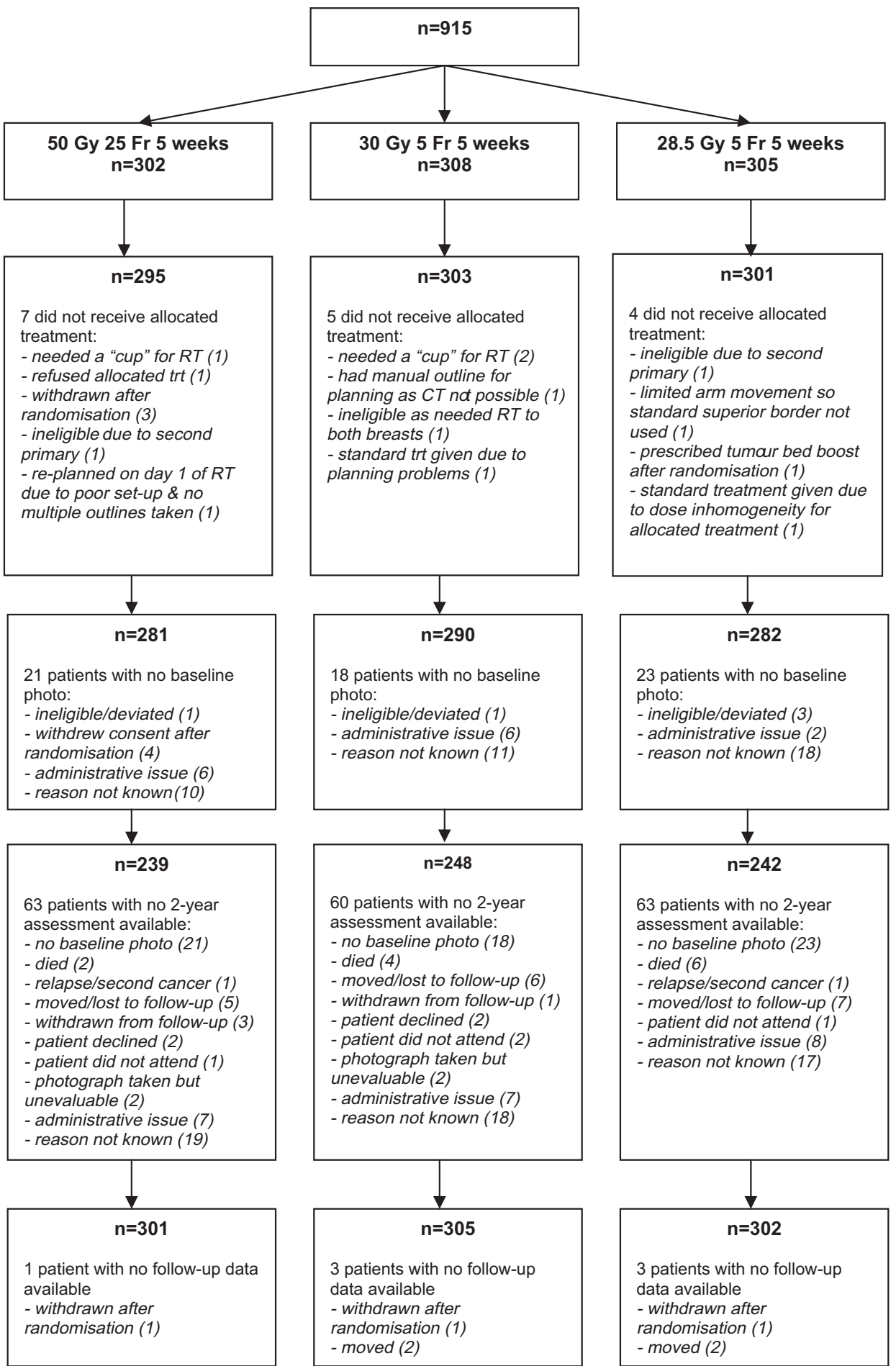

Fig. 1. Trial profile for FAST Trial. 
Table 2

Acute skin reactions during treatment by fractionation schedule.

\begin{tabular}{|c|c|c|c|c|}
\hline \multirow[t]{2}{*}{ RTOG grade } & \multicolumn{3}{|c|}{ Fractionation schedule } & \multirow[t]{2}{*}{ Total (\%) } \\
\hline & 50 Gy (\%) & 30 Gy (\%) & $28.5 \mathrm{~Gy}(\%)$ & \\
\hline $0=$ No visible change & $8(7.3)$ & $28(25.2)$ & $42(39.6)$ & $78(23.9)$ \\
\hline 1 = Faint $/$ dull erythema & $51(46.4)$ & $67(60.4)$ & $53(50.0)$ & $171(52.3)$ \\
\hline $2=$ Tender $/$ bright erythema \pm dry desquamation & $39(35.5)$ & $13(11.7)$ & $9(8.5)$ & $61(18.7)$ \\
\hline $3=$ Patchy moist desquamation, moderate oedema & $12(10.9)$ & $3(2.7)$ & $2(1.9)$ & $17(5.2)$ \\
\hline $4=$ Confluent moist desquamation, pitting oedema & 0 & 0 & 0 & 0 \\
\hline Total with known RTOG grade for acute skin reaction & $110(100)$ & $111(100)$ & $106(100)$ & $327(100)$ \\
\hline Not recorded ${ }^{\mathrm{a}}$ & 187 & 192 & 196 & 575 \\
\hline Not known & 5 & 5 & 3 & 13 \\
\hline Total randomised & 302 & 308 & 305 & 915 \\
\hline
\end{tabular}

a Acute toxicity data was not collected from the beginning of the trial.

Table 3

Change in photographic breast appearance at 2 years by fractionation schedule.

\begin{tabular}{|c|c|c|c|c|c|c|c|}
\hline & \multicolumn{3}{|c|}{ Fractionation schedule } & \multirow{2}{*}{$\begin{array}{l}\text { Total, } \\
N=729 \\
(\%)\end{array}$} & \multirow{2}{*}{$\begin{array}{l}\text { Risk ratio for } 30 \mathrm{~Gy} \text { vs } 50 \mathrm{~Gy} \\
(95 \% \mathrm{CI}), p \text {-value for trend }\end{array}$} & \multirow{2}{*}{$\begin{array}{l}\text { Risk ratio for } 28.5 \mathrm{~Gy} \text { vs } 50 \mathrm{~Gy} \\
(95 \% \mathrm{CI}), p \text {-value for trend }\end{array}$} & \multirow{2}{*}{$\begin{array}{l}\text { Risk ratio for } 30 \text { Gy vs } 28.5 \mathrm{~Gy} \\
(95 \% \mathrm{CI}), p \text {-value for trend }\end{array}$} \\
\hline & $\begin{array}{l}50 \mathrm{~Gy} \\
N=239 \\
(\%)\end{array}$ & $\begin{array}{l}30 \mathrm{~Gy} \\
N=248 \\
(\%)\end{array}$ & $\begin{array}{l}28.5 \mathrm{~Gy}, \\
N=242 \\
(\%)\end{array}$ & & & & \\
\hline $\begin{array}{l}\text { No } \\
\text { change }\end{array}$ & $189(79.1)$ & $160(64.5)$ & $184(76.0)$ & $533(73.1)$ & $1, p<0.001$ & $1, p=0.26$ & $1, p=0.002$ \\
\hline Mild change & $46(19.2)$ & $65(26.2)$ & 49 (20.2) & $160(22.0)$ & $1.48(1.06-2.05)$ & $1.07(0.75-1.54)$ & $1.37(1.00-1.90)$ \\
\hline $\begin{array}{l}\text { Marked } \\
\text { change }\end{array}$ & $4(1.7)$ & $23(9.3)$ & $9(3.7)$ & $36(4.9)$ & $6.06(2.14-17.20)$ & $2.25(0.70-7.18)$ & $2.70(1.28-5.67)$ \\
\hline
\end{tabular}

of clinically-assessed adverse effects in the breast. Moderate or marked adverse effects in the breast (including shrinkage, induration, telangiectasia, oedema and other) were reported in 155 patients overall. Estimates of 3-year rates of any moderate or marked adverse effect in the breast were 9.5\% (95\% CI 6.5-13.7\%) for $50 \mathrm{~Gy}, 17.3 \%$ (95\% CI $13.3-22.3 \%$ ) for $30 \mathrm{~Gy}$ and $11.1 \%$ (95\% CI $7.9-15.6 \%$ ) for $28.5 \mathrm{~Gy}$; the rate in the $30 \mathrm{~Gy}$ group was significantly higher than in $50 \mathrm{~Gy}$ (logrank test $p<0.001$ ) and in 28.5 Gy (logrank test $p<0.006$ ), with similar rates in the 50 and $28.5 \mathrm{~Gy}$ groups (logrank test $p=0.18$ ). Most of the moderate or marked adverse effects in the breast were due to shrinkage $(n=106)$ and induration $(n=40)$, with few reports of oedema $(n=27)$ and telangiectasia $(n=15)$. Results for shrinkage and induration are shown in Figs. 2 and 3, indicating similar rates in the 50 and $28.5 \mathrm{~Gy}$ schedules but higher rates for $30 \mathrm{~Gy}$.

Change in photographic breast appearance, the primary endpoint, gave an estimate of $\alpha / \beta$ of $2.6 \mathrm{~Gy}$ (95\% CI 1.4-3.7). Using this estimate, the isoeffect doses expressed in $2.0 \mathrm{~Gy}$ equivalents for 30 and $28.5 \mathrm{~Gy}$ in 5 fractions are 56.3 and $51.6 \mathrm{~Gy}$, respectively. Adjustment for breast size and surgical deficit at baseline made little difference to the $\alpha / \beta$ estimate viz. $2.5 \mathrm{~Gy}$ (95\% CI 1.2-3.7). Estimates of $\alpha / \beta$ for the physician-assessed adverse effects are similar to the result for the photographic endpoint (Table 4).

Thirty-two patients were referred to specialist clinics for a possible radiotherapy-related adverse effect ( 10 in $50 \mathrm{~Gy}, 14$ in $30 \mathrm{~Gy}$ and 8 in $28.5 \mathrm{~Gy}$ ), including lymphoedema ( $n=25$ comprising 13 breast and $12 \mathrm{arm})$, possible rib fracture $(n=1)$, breast pain $(n=1)$, cellulitis $(n=1)$, late onset of asthma $(n=1)$, atrial fibrillation $(n=1)$, irregular heart beat $(n=1)$ and cough $(n=1)$. Of the 908 patients with follow-up data available, there were 2 local relapses (in breast skin or parenchyma), 3 regional relapses (in axilla or supraclavicular fossa), 17 metastases and 8 patients with a reported second primary cancer. Twenty-three patients had died, 10 of which were breast cancer-related (Table 5).

\section{Discussion}

The FAST Trial was designed to identify a 5-fraction schedule of whole breast radiotherapy delivered using once-weekly fractions that is equivalent, in terms of late adverse effects in the breast, to a standard regimen of $50 \mathrm{~Gy}$ in 25 fractions. Once-weekly fractions were chosen to minimise confounding of treatment outcome measures by differences in overall treatment time. The estimate of $\alpha / \beta=2.6 \mathrm{~Gy}$ (95\% CI 1.4-3.7) for change in photographic breast appearance is very close to estimates of breast hardness and shrinkage based on the annual physician assessments, see Table 3 . Assuming an $\alpha / \beta$ value of $2.6 \mathrm{~Gy}$, the two test dose levels of 28.5 and $30 \mathrm{~Gy}$ in 5 fractions are equivalent to 51.4 and $58.2 \mathrm{~Gy}$, respectively, delivered in $2.0 \mathrm{~Gy}$ equivalents. The $\alpha / \beta$ values are consistent with an updated analysis (2010) of the START pilot and START A trials, which generated an adjusted $\alpha / \beta$ value for late change in photographic breast appearance of $3.1 \mathrm{~Gy} \mathrm{(95 \%} \mathrm{CI} \mathrm{2.0-}$ 4.3) [18]. Patient eligibility for the FAST Trial focused on factors related to patient age and tumour stage associated with a relatively low risk of local tumour relapse, selecting a population with the least to lose from a loss of tumour control after hypofractionated radiotherapy. There was no recommendation in the protocol that women with known risk factors for late adverse effects, such as those with very large breast size, should be excluded [19-21]. The rates of $20.9 \%, 35.5 \%$ and $24.0 \%$ for any change (mild or marked) in photographic breast appearance for the 50,30 and $28.5 \mathrm{~Gy}$ groups, respectively, compare with $24.2 \%$ for the $50 \mathrm{~Gy}$ groups of the START Trials A and B combined.

The $\alpha / \beta$ values for late adverse effects generated by the FAST and START trials are in close agreement with each other, although fractionation sensitivity might be slightly higher $(\alpha / \beta$ value slightly lower) when fraction sizes of 5-6 Gy are compared with $2.0 \mathrm{~Gy}$, for two reasons. Moist desquamation is less common when hypofractionation is used, reflecting a response to lower total dose, and this 




Fig. 2. Kaplan-Meier plot of time to moderate/marked physician assessed breast shrinkage, by fractionation schedule. $95 \% \mathrm{CI}=95 \%$ confidence interval. Events reported at 1 year were excluded from the analysis.

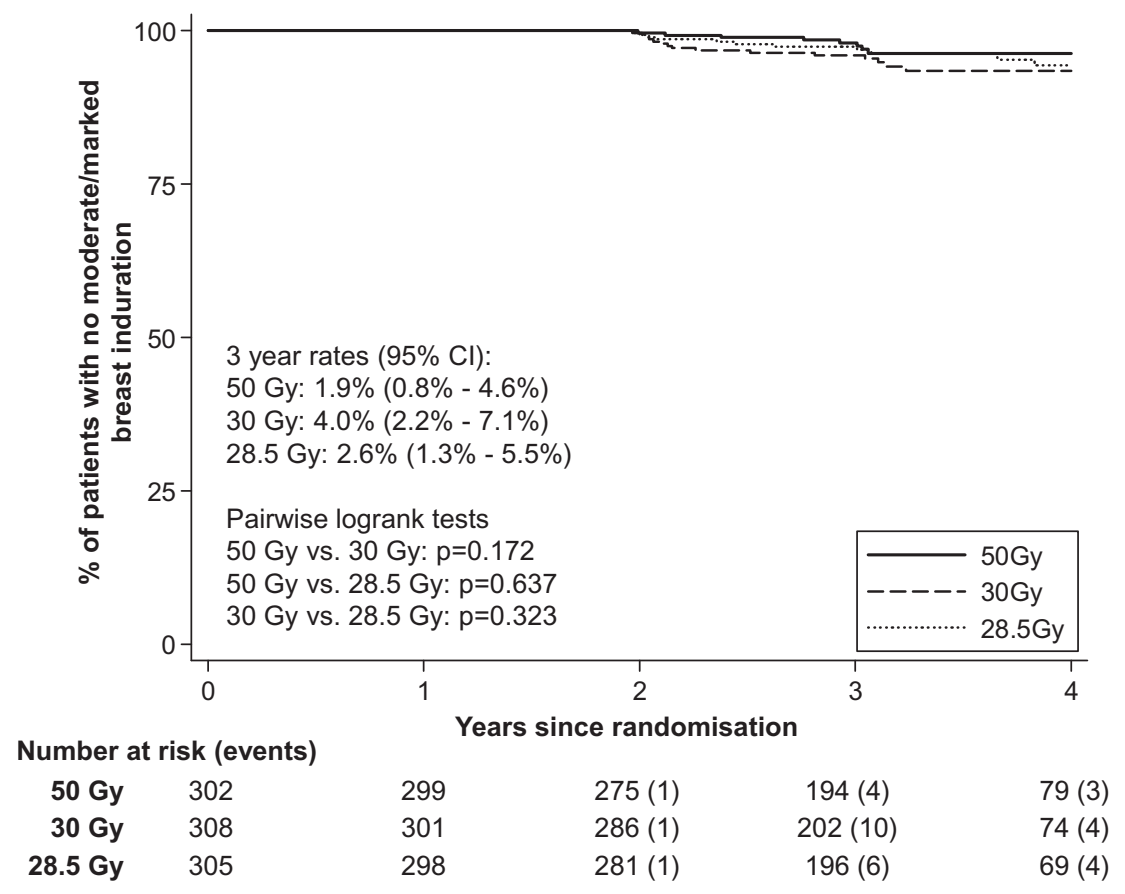

Fig. 3. Kaplan-Meier plot of time to moderate/marked physician assessed breast induration, by fractionation schedule. $95 \% \mathrm{CI}=95 \%$ confidence interval. Events reported at 1 year were excluded from the analysis.

reduces late consequential effects [22]. So-called consequential late damage, most obviously skin atrophy, telangiectasia and induration in the inframammary fold, reflects a severe disruption of the basal epidermis associated with granulation tissue and variable degrees of scarring. It is difficult to quantify the contribution of consequential effects to overall breast shrinkage, distortion and induration, but they share the high $\alpha / \beta$ value of the early epithelial reactions. In other words, late consequential effects tend to 'artificially' increase the $\alpha / \beta$ value when conventional fractionation is used in heavy-breasted women. A second process that might slightly reduce the $\alpha / \beta$ estimate when large fractions are used is the increased effect of dose inhomogeneity on dose intensity as fraction size increases, so-called 'triple trouble' [23]. Dose inhomogeneity ('double trouble') is always bad, and is important even when $2.0 \mathrm{~Gy}$ fractions are used [24,25]. Simple calculations show that the added impact of hypofractionation (triple trouble) can be ignored for practical purposes provided full dose compensation is applied. 
Table 4

Estimates of $\alpha / \beta$ and isoeffect doses in $2.0 \mathrm{~Gy}$ equivalents $\left(\mathrm{EQD}_{2}\right)$ for adverse event endpoints.

\begin{tabular}{|c|c|c|c|c|c|}
\hline \multirow[t]{2}{*}{ Adverse events } & \multirow[t]{2}{*}{$\begin{array}{l}\alpha / \beta \text { estimate } \\
(\mathrm{Gy})\end{array}$} & \multicolumn{2}{|c|}{$\begin{array}{l}\text { 95\% confidence } \\
\text { interval }(\mathrm{Gy})\end{array}$} & \multirow[t]{2}{*}{$\begin{array}{l}\mathrm{EQD}_{2} \text { for } 30 \mathrm{~Gy} \\
\text { schedule }(\mathrm{Gy})\end{array}$} & \multirow[t]{2}{*}{$\begin{array}{l}\mathrm{EQD}_{2} \text { for } 28.5 \mathrm{~Gy} \\
\text { schedule }(\mathrm{Gy})\end{array}$} \\
\hline & & $\begin{array}{l}\text { Lower } \\
\text { limit }\end{array}$ & $\begin{array}{l}\text { Upper } \\
\text { limit }\end{array}$ & & \\
\hline \multicolumn{6}{|l|}{ Photographic assessments } \\
\hline Change in photographic breast appearance at 2 years & 2.6 & 1.4 & 3.7 & 56.3 & 51.6 \\
\hline $\begin{array}{l}\text { Change in photographic breast appearance at } 2 \text { years, adjusted for breast } \\
\text { size and surgical deficit }\end{array}$ & 2.5 & 1.2 & 3.7 & 57.0 & 52.2 \\
\hline \multicolumn{6}{|l|}{ Physician assessments } \\
\hline Any adverse effect in the breast & 2.3 & 1.2 & 3.4 & 57.7 & 52.8 \\
\hline Breast shrinkage & 2.5 & 1.4 & 3.7 & 56.5 & 51.8 \\
\hline Breast induration & 2.4 & 0 & 5.3 & 57.3 & 52.5 \\
\hline
\end{tabular}

Table 5

Relapses, second primary cancers and deaths by fractionation schedule.

\begin{tabular}{lllrr}
\hline & \multicolumn{3}{l}{ Fractionation schedule } & Total \\
\cline { 2 - 3 } & $50 \mathrm{~Gy}$ & $30 \mathrm{~Gy}$ & $28.5 \mathrm{~Gy}$ & \\
\hline Relapses & 2 & 0 & 0 & 2 \\
$\quad$ Local (breast skin or parenchyma) & 2 & & & \\
Regional (axilla or supraclavicular fossa) & 1 & 0 & 2 & 3 \\
Distant & 5 & 2 & 10 & 17 \\
Second primary cancer & 3 & 3 & 2 & 8 \\
Deaths & 6 & 5 & 12 & 23 \\
Breast cancer & 2 & 2 & 6 & 10 \\
Other cause $^{\mathrm{a}}$ & 4 & 3 & 6 & 13 \\
\hline
\end{tabular}

${ }^{a}$ Deaths from other causes included 4 cardiac-related events, 2 of which were in patients who received left-sided radiotherapy.

The trial was not powered to test local tumour control differences between treatment groups, and only two local relapses (both in the control group) have so far been reported in the breast with a median follow up of 3.1 years. This extremely low rate $(0.2 \%)$ reflects the patient demographics, tumour characteristics, careful attention to microscopic excision margins and the use of adjuvant endocrine therapy in the study population. It seems unlikely that longer follow up will generate enough events to contribute to any meaningful estimate of $\alpha / \beta$ value for tumour control. It is too early to tell whether the current imbalance in rates of metastases and deaths between the treatment groups will persist with further follow-up. Despite this, it is apparent from existing mature data that the $\alpha / \beta$ value for tumour control is likely to be much lower than 10 Gy [26].

In conclusion, a 5-fraction schedule of whole breast radiotherapy delivered in once-weekly fractions has been identified that is equivalent to a conventionally fractionated regimen in terms of change in breast appearance at 2 years and annual clinical assessments of a range of adverse effects in the breast recorded at a median of 3.1 years. No patient in this trial required radiotherapy to the lymphatic pathways. Longer follow up to a minimum of 5 years is needed for reliable estimates of iso-effect. Meanwhile, a pilot study of 30 patients treated with $30 \mathrm{~Gy}$ in 5 fractions in 15 days reported acceptable levels of late adverse effects at 5 years follow up [27]. A subsequent phase 3 randomised trial (FAST-Forward) will test two dose levels of a 5 -fraction regimen delivered in 1 week against $40 \mathrm{~Gy}$ in 15 fractions over 3 weeks in women requiring adjuvant radiotherapy to the breast, chest wall or reconstructed breast after primary surgery.

\section{Contributors (TMG)}

J.R. Yarnold (JRY, Chief Investigator and Chair) and J.M. Bliss (JMB) were responsible for the trial design, trial management, data interpretation, and manuscript writing. J.S. Haviland (JSH) and J.P. Morden (JPM) did the main analyses and contributed to data interpretation and manuscript writing. R. Kaggwa, S. Simmons and M.A. Sydenham were responsible for the trial coordination and data collection, and contributed to data interpretation and manuscript writing. K. Venables and Y. Tsang were responsible for the design and conduct of the quality assurance programme and contributed to the trial management, data interpretation, and manuscript writing. All other TMG members contributed to trial design, trial management and manuscript review.

\section{FAST Writing Committee}

The FAST Writing Committee are all members of the Trial Management Group: Rajiv K. Agrawal (Shrewsbury Hospital); Abdulla Alhasso (Beatson Cancer Centre); Peter J. Barrett-Lee (Velindre Hospital, Cardiff); Judith M. Bliss (ICR-CTSU, Institute of Cancer Research); Peter Bliss (Torbay Hospital); David Bloomfield (Royal Sussex County Hospital); Joanna Bowen (Cheltenham General Hospital); A. Murray Brunt (University Hospital of North Staffordshire); Ellen Donovan (Royal Marsden Hospital, Sutton); Marie Emson (ICR-CTSU, Institute of Cancer Research); Andrew Goodman (Royal Devon and Exeter Hospital); Adrian Harnett (Norfolk and Norwich University Hospital); Joanne S. Haviland (ICR-CTSU, Institute of Cancer Research); Ronald Kaggwa (ICR-CTSU, Institute of Cancer Research); James P. Morden (ICR-CTSU, Institute of Cancer Research); Anne Robinson (Southend Hospital); Sandra Simmons (ICR-CTSU, Institute of Cancer Research); Alan Stewart (Christie Hospital); Mark A. Sydenham (ICR-CTSU, Institute of Cancer Research); Isabel Syndikus (Clatterbridge Centre for Oncology); Jean Tremlett (Royal Sussex County Hospital); Yat Tsang (Mount Vernon Hospital); Duncan Wheatley (Royal Cornwall Hospital); Karen Venables (Mount Vernon Hospital); John R. Yarnold (Institute of Cancer Research, Royal Marsden Hospital, Sutton).

\section{The FAST Trialists' Group}

In addition to the Trial Management Group (named as Writing Committee above), the following groups are all part of the FAST collaboration:

Principal and main co-investigators according to centre (No. of patients recruited): Cheltenham General Hospital, Cheltenham (2), K. Benstead, J.R. Owen; Gloucester Royal Hospital, Gloucester (2), K. Benstead; Worcestershire Royal Infirmary, Worcester (6), J. Bowen, R. Counsell; Christie Hospital, Manchester (12), A. Stewart; Clatterbridge Centre for Oncology, Bebington (6), I. Syndikus; Warrington and Halton Hospitals, Warrington (18), I. Syndikus; Ipswich Hospital, Ipswich (17), E. Sherwin; Leeds General Hospital, Leeds (5), S. Kumar Mid-Yorks Hospitals, Wakefield (4), S. Kumar, F. Roberts; Norfolk and Norwich University Hospital, Norwich (27), A. Harnett, 
A. Bulman; James Paget, Norfolk and Norwich (25), A. Harnett, A. Bulman; University Hospital of North Staffordshire, Stoke-on-Trent (112), A.M. Brunt, A. Al Niaimi; Royal Marsden Hospital, Sutton (75), J.R. Yarnold, D. Tait, A. Rostom, M. Dryzmala; Royal Cornwall Hospital, Truro (109), D. Wheatley, A. Thomson, T. Hurst; Royal Devon and Exeter Hospital, Exeter (61), A. Goodman, A. Hong, P. Bliss; North Devon Hospital, (20), A. Hong; Burnley General Hospital, Burnley (14), M. Hogg, W. Appel; Blackpool Royal Infirmary, Blackpool (6), Royal Preston, A. Hindley, S. Susnerwala; Royal Shrewsbury Hospital, Shrewsbury (36), R.K. Agrawal; Southend General Hospital, Southend (66), A. Robinson; Basildon University Hospital, Basildon (3), C. Trask; Torbay District General Hospital, Torbay (58), P. Bliss, A. Goodman; Velindre Hospital, Cardiff (42), J. Abraham, C. Gaffney, P.J. Barrett-Lee; Royal Gwent Hospital (7), J. Abraham, C. Gaffney, P.J. Barrett-Lee; Royal Glamorgan Hospital, (4), J. Abraham; Royal Sussex County Hospital, Brighton (34), D. Bloomfield, R. Simcock; Worthing Hospital, Worthing (41), S. Mitra; Eastbourne Hospital, Eastbourne (2), A. Robinson; Queens Hospital, Romford (9), M. Quigley, E. Sims; Beatson Oncology Centre, Glasgow (85), A. Alhasso, D. Ritchie; Victoria Infirmary, Glasgow (2), A. Alhasso; Crosshouse Hospital, Kilmarnock (5), A. Alhasso, D. Ritchie.

Trial Steering Committee: Independent members: M. Mason (Chair, Velindre Hospital, Cardiff), D. Thwaites (St James' University Hospital, Leeds), M. Saunders (Mount Vernon Hospital retired), A. Puroshotham (Guys and St Thomas' Hospitals), J. Barrett (Royal Berkshire NHS Foundation Trust).

Independent Data Monitoring Committee: H. Lucraft (Chair, Freeman Hospital, Newcastle), M. Sydes (MRC Clinical Trials Unit, London), I. Turesson (Akadamiska Sjukhuset, Uppsala, Sweden).

\section{Conflict of interest statement}

The authors declare no conflict of interest.

\section{Acknowledgements}

We thank all the patients who participated in this study, and the doctors, nurses, radiographers, physicists and data managers at the participating centres. We acknowledge the support of The Royal College of Radiologists (UK). We acknowledge NHS funding to the NIHR Biomedical Research Centre. We thank Cancer Research UK who provide the core grant for ICR-CTSU (Grant C1491/A9895). The Cancer Research UK number for the FAST Trial is CRUKE/04/015.

\section{References}

[1] Thames HD, Bentzen SM, Turesson I, Overgaard M, van den Bogaert W. Timedose factors in radiotherapy: a review of the human data. Radiother Oncol 1990;19:219-35.

[2] Brenner DJ, Martinez AA, Edmundson GK, Mitchell C, Thames HD, Armour EP. Direct evidence that prostate tumors show high sensitivity to fractionation (low alpha/beta ratio), similar to late-responding normal tissue. Int J Radiat Oncol Biol Phys 2002;52:6-13.

[3] Cohen L. Radiotherapy in breast cancer. I. The dose-time relationship theoretical considerations. Br J Radiol 1952;25:636-42.

[4] Douglas BG. Superfractionation: its rationale and anticipated benefits. Int J Radiat Oncol Biol Phys 1982;8:1143-53.

[5] Owen JR, Ashton A, Bliss JM, et al. Effect of radiotherapy fraction size on tumour control in patients with early-stage breast cancer after local tumour excision: long-term results of a randomised trial. Lancet Oncol 2006;7:467-71.

[6] Bentzen SM, Agrawal RK, Aird EG, et al. The UK Standardisation of Breast Radiotherapy (START) Trial A of radiotherapy hypofractionation for treatment of early breast cancer: a randomised trial. Lancet Oncol 2008;9:331-41.

[7] Bentzen SM, Agrawal RK, Aird EG, et al. The UK Standardisation of Breast Radiotherapy (START) Trial B of radiotherapy hypofractionation for treatment of early breast cancer: a randomised trial. Lancet 2008;371:1098-107.

[8] Whelan TJ, Pignol JP, Levine MN, et al. Long-term results of hypofractionated radiation therapy for breast cancer. $\mathrm{N}$ Engl J Med 2010;362:513-20.

[9] Jones B, Dale RG, Deehan C, Hopkins KI, Morgan DA. The role of biologically effective dose (BED) in clinical oncology. Clin Oncol 2001;13:71-81.

[10] Turesson I. The progression rate of late radiation effects in normal tissue and its impact on dose-response relationships. Radiother Oncol 1989;15:217-26.

[11] Courdi A, Ortholan C, Hannoun-Levi JM, et al. Long-term results of hypofractionated radiotherapy and hormonal therapy without surgery for breast cancer in elderly patients. Radiother Oncol 2006;79:156-61.

[12] Kirova YM, Campana F, Savignoni A, et al. Breast-conserving treatment in the elderly: long-term results of adjuvant hypofractionated and normofractionated radiotherapy. Int J Radiat Oncol Biol Phys 2009;75:76-81.

[13] ICRU. Prescribing, recording and reporting photon beam therapy. International Commission on Radiation Units and Measurements (ICRU); 1993.

[14] ICRU. Prescribing, recording and reporting photon beam therapy. International Commission on Radiation Units and Measurements (ICRU); 1999.

[15] Haviland JS, Ashton A, Broad B, et al. Evaluation of a method for grading late photographic change in breast appearance after radiotherapy for early breast cancer. Clin Oncol (R Coll Radiol) 2008;20:497-501.

[16] National Cancer Institute. CTEP Cancer Therapy Evaluation Program. Common Toxicity Criteria (CTC) Version 2.0; 1999. <http://www.ctep.info.nih.gov/ protocolDevelopment/electronic_applications/docs/ctcv20_4-30-992.pdf >.

[17] Yarnold J, Ashton A, Bliss J, et al. Fractionation sensitivity and dose response of late adverse effects in the breast after radiotherapy for early breast cancer: long-term results of a randomised trial. Radiother Oncol 2005;75:9-17.

[18] Kirby AM, Evans PM, Donovan EM, Convery HM, Haviland JS, Yarnold JR. Prone versus supine positioning for whole and partial-breast radiotherapy: a comparison of non-target tissue dosimetry. Radiother Oncol 2010;96:178-84.

[19] Moody AM, Mayles WP, Bliss JM, et al. The influence of breast size on late radiation effects and association with radiotherapy dose inhomogeneity. Radiother Oncol 1994;33:106-12.

[20] Neal AJ, Yarnold JR. Estimating the volume of lung irradiated during tangential breast irradiation using the central lung distance. Br J Radiol 1995;68:1004-8.

[21] Vrieling C, Collette L, Fourquet A, et al. The influence of patient, tumor and treatment factors on the cosmetic results after breast-conserving therapy in the EORTC 'boost vs. no boost' trial. EORTC Radiotherapy and Breast Cancer Cooperative Groups. Radiother Oncol 2000;55:219-32.

[22] Dorr W, Hendry JH. Consequential late effects in normal tissues. Radiother Oncol 2001;61:223-31.

[23] Yarnold J, Bentzen SM, Coles C, Haviland J. Hypofractionated whole-breast radiotherapy for women with early breast cancer: myths and realities. Int J Radiat Oncol Biol Phys 2011;79:1-9.

[24] Lee SP, Leu MY, Smathers JB, McBride WH, Parker RG, Withers HR. Biologically effective dose distribution based on the linear quadratic model and its clinical relevance. Int J Radiat Oncol Biol Phys 1995;33:375-89.

[25] Donovan E, Bleakley N, Denholm E, et al. Randomised trial of standard 2D radiotherapy (RT) versus intensity modulated radiotherapy (IMRT) in patients prescribed breast radiotherapy. Radiother Oncol 2007;82:254-64.

[26] Qi XS, White J, Li XA. Is $\alpha / \beta$ for breast cancer really low? Radiother Oncol 2011. doi:10.1016/j.radonc.2011.01.010.

[27] Martin S, Mannino M, Rostom A, et al. Acute toxicity and 2-year adverse effects of $30 \mathrm{~Gy}$ in five fractions over 15 days to whole breast after local excision of early breast cancer. Clin Oncol 2008;20:502-5. 